\title{
A emergência da Educação Especial como campo de saber e suas atualizações para o presente
}

Leandra Bôer Possa*

\section{Resumo}

A centralidade do sujeito como objeto e protagonista da produção dos saberes na modernidade narra a história e produção de conhecimentos verdadeiros, a descrição de um lugar da normalidade em contraponto com a anormalidade e um ordenado de um campo de saber chamado de Educação Especial. Esta é a tônica deste artigo que pretende olhar para a atualidade dos relatórios em que Jean Itard relata sua atuação e o consequente processo educativo de Victor, o menino selvagem. Sob a perspectiva das noçôes de ordenamento dos saberes e normalização, retirada dos estudos foucautianos, realiza-se uma analítica dos fragmentos dos relatórios de Jean Itard como acontecimentos que possibilitam compreender de que forma essas experiências, do início do século XIX, constituem-se contemporâneas para o campo de saber da Educação Especial.

Palavras-chave: Ordem do saber; Normalização; Educação Especial.

\footnotetext{
* Professora doutora da Universidade Federal de Santa Maria, Santa Maria, Rio Grande do Sul, Brasil - Bolsista de Pós-Doutorado CAPES.
} 


\section{The emergence of Special Education as a learning field and updates for the present}

\section{Abstract}

The centrality of the subject as an object and the knowledge production's protagonist in modernity, tells the story and the production of true knowledge, the description of a place of normality as opposed to the abnormality and ordering of the field of knowledge called Special Education. This is the subject of this article, which intends to look at Jean Itard's timeline reports where are described his operations and the consequent educational process of Victor, the wild boy. From the ordenation's point of view and the notion of normalization, withdrawn from foucautian studies, it was led to analyze fragments of Jean Itard reports as an event that allow to understand how these experiences from the early nineteenth century, constitute contemporary to the field of knowledge of Special Education.

Keywords: Order of knowledge; Normalization; Special Education.

[...] a modernidade começa quando o sujeito humano começa a existir no interior de seu organismo, na concha de sua cabeça, na armadura de seus membros e em meio a toda a nervura de sua fisiologia; quando ele começa a existir no coraçáo de seu trabalho cujo o princípio o domina e cujo produto lhe escapa; quando aloja seu pensamento nas dobras de uma linguagem, [...] A cultura moderna pode pensar o homem porque ela pensa o finito a partir dele próprio. (FOUCAULT, 2007, p. 438).

\section{Mais que uma Introdução: o cenário para pensar}

É na época moderna que a Educação Especial se constitui num campo de saber. Num discurso em que a história é representativa e fundamentada no pressuposto da evolução, do progresso e da superação sucessiva e contínua do presente em relação ao passado, que este campo de saber vem sendo representado. A cronologia e a evolução histórica parecem ser a "origem" que rege a maioria dos estudos e a representação da Educação Especial, por exemplo:

A história da ideia de deficiente mental acompanha de perto a evolução da conquista e formulação dos "direitos humanos" que se insere, por sua vez, na trajetória da filosofia humanista. (PESSOTTI, 1984, p. 1).

A proposta revolucionária de incluir todos os alunos em uma única modalidade educacional, o ensino regular, tem encontrado outras barreiras, dentre as quais se destaca a cultura assistencialista e terapêutica da Educação Especial [que para a autora consiste no passado da Educaçáo Especial]. (MANTOAN, 2007, p. 11).

Mesmo considerando a grande evolução na educação das pessoas com necessidade especiais, que durante muitos séculos e décadas foram relegadas à segregaçáo, abandono e formas de atendimento assistencialistas, pode-se perceber, através de iniciativas isoladas, 
que até o momento as açóes educacionais no sentido de garantir a educação de qualidade para essa população ainda caminham vagarosamente. (DUARTE, 2008, p. 31).

A inclusão como antônima da exclusão se configura nos discursos das atuais práticas em Educação Especial. É o ponto cronológico do presente que permite revisitar, desvelar e entender o passado das práticas da Educação Especial e que possibilitaria reconhecer, no presente, a melhor prática, o melhor modo de ser e conduzir as relaçốes sociais e educacionais da pessoa com deficiência.

$\mathrm{Na}$ ordem da cronologia, a inclusão se estabelece a partir de um conhecimento presente que ganha, pelos princípios da evolução, progresso e superação, um estatuto de verdade. $\mathrm{O}$ atual se qualifica como melhor e mais avançado no jogo da continuidade do pensamento e das práticas.

A perspectiva de superação do passado aponta o presente, mas, sobretudo, o futuro como lugar e tempo naturalizado para aquilo que seria o melhor. É um modelo de pensamento que se projeta numa produção discursiva do dever ser e é fabricado pela naturalização e historicização de uma verdade a ser realizada e desfrutada.

É possível dizer que esta ordem de produção consiste num modelo de pensamento que está para além da Educação Especial, mas também nele ela se organiza. Essa ordem como efeito configura um modo de ser e estar se produzindo na atualidade, opera para determinar a história, as relaçóes de saber-poder, os processos de objetivação e subjetivação que foram inventados na época moderna. Uma época que aponta o final do século XVIII e início do século XIX como momento em que se inaugura um novo modo de produção do saber, que cria as condiçóes de possibilidades para o ser humano ser reconhecido como objeto de conhecimento e sujeito do conhecimento; um sujeito que pode produzir a história. Um duplo modo de ser do sujeito que passa a desempenhar função dupla na constituição do saber moderno (FOUCAULT, 2007) ${ }^{1}$.

Para Candiotto, um "outro ponto de sustentação para [...] história" (2007, p. 5); pois é uma história que sustenta a existência dos saberes naquilo que lhe deu as condiçóes de possibilidade para se constituírem discursos verdadeiros. Náo interessa, para neste cenário, a "história das ciências que parte de fundamentos atuais de verdade e de objetos específicos, [pois os] diversos objetos de saber constituídos numa mesma época não são estudados nos termos de uma leitura retrospectiva" (CANDIOTTO, 2007, p. 6), pois o que interessa é pensar sobre a ordem e sob que condiçôes esses saberes se constituem.

Utilizando desta prerrogativa podemos dizer que não nos interessa a história evolutiva da Educação Especial, pois o que nos interessa é pensá-la a partir de certas condiçóes de possibilidade para sua emergência como campo de conhecimento; as condiçóes de possibilidade da Educação Especial num espaço da ordem discursiva e da história.

A noçáo da ordem se constitui de um enquadramento composto de regras de validação, que atua como elemento "fundador" dos saberes, que dizem sobre forma- 
ção dos objetos a conhecer e que considera a posiçẫo dos sujeitos e a distribuição dos conceitos. Para Foucault (2007), a possibilidade de nomear, falar e pensar sobre as coisas só é possível porque estas sofrem a ação da ordem, de uma ordenação capaz de reuni-la num espaço comum e homogêneo, uma ordem que permite localizá-la. Espaço em que se torna possível nomear, falar e pensar as coisas.

É, pois, a ordem que se inaugura entre o final do século XVIII e início do século XIX que emerge o homem racional como aquele que pela experiência, pelo trabalho e pela linguagem torna-se capaz de representar a realidade, considerando que tudo aquilo que não pode ser descrito neste quadro, numa ordem, é excluído, é loucura e é próprio da interdição.

É numa ordem que presentifica o homem constituindo-o sujeito manifesto da positividade dos saberes que Foucault (2007) empreende a perspectiva da descontinuidade como modo de saber que se movimentava em "colocar fundamentalmente em questáo [...] a relação do sentido com a forma de verdade e a forma de ser" (p. 287)

Foucault (2007) mostra que o modo de verificação e formulação do saber na época moderna muda - em relação a antiguidade - pois produz uma descontinuidade no modo de conhecer. Não mais a representação do ser e das coisas, mas a representação da representação dos mesmos. Pelos princípios da descontinuidade, da invisibilidade e da profundidade, tem-se a possibilidade de adentrar no espaço tridimensional do empírico, da vida, dos objetos, seres e coisas; a possibilidade de combinação e ordenação, não mais uma ordem das coisas e das palavras, mas a ordem do conhecimento que permitiria saber sobre as coisas, os seres e a vida. A época moderna teria colocado em funcionamento um modo de produção do saber assentada na organização que separa o objeto do modo de conhecer e cria na ordem metodológica para a determinação da verdade.

É pela descontinuidade dos modos de saber que o ser humano se torna objeto do saber, pois é com a possibilidade de conhecer em profundidade, verificando o interior e penetrando no espaço tridimensional do corpo e do funcionamento das condutas que se pode produz conhecimento e saberes verdadeiros sobre o ser humano, se pode produzir as ciências humanas. Para Machado (2006), a tese de Foucault nos aponta para o a priori histórico que coloca em evidência o aparecimento das ciências humanas e nos ajuda a pensar que: ao se estabelecer "uma correlaçáo entre o homem como objeto e o homem como sujeito de conhecimento" tem-se a "dupla função que seu modo de ser desempenha no saber moderno". (MACHADO, 2006, p. 122).

Esta nova ordem que passa a operar na produção do saber moderno faz do homem uma invençáo que se constitui do conhecimento, mas, sobretudo, que passa a ser a sede, espaço inaugural e fundacional do conhecimento. O saber moderno na repetição desta dupla função do sujeito só se torna possível porque "a cultura moderna pode pensar o homem porque ela pensa o finito a partir dele" (FOUCAULT, 2007, p. 438). 
É a descoberta do ser humano- e com isso da morte na ordem da vida (FOUCAULT, 2004); a guerra na ordem da paz (FOUCAULT, 2008); a conduta na ordem da regulação (FOUCAULT, 1987) - como ser finito, possível de ser determinado em sua existência corporal, em sua força laboral e em seu limite para dizer/falar, que constitui a positividade do saber moderno. Através da morte do homem, pode-se saber sobre o cérebro e o corpo humano; através do trabalho como atividade econômica, pode-se saber sobre suas necessidades para que possa escapar da morte; através das palavras que não estão coladas às coisas pode-se ter a possibilidade de produzir racionalmente saberes que reclamam seu devir numa ordem de inteligibilidade.

O homem como efeito da constituição do saber moderno não pode ser pensado fora da verdade, fora de uma configuração epistêmica. Um homem empírico e um homem outro que lhe serve de sombra, o outro do homem, a verdade do homem que serve de direção, aproxima e mantém a distancia do outro. Saber moderno pois "avança naquela direção em que o outro do homem deve tornar-se o Mesmo que ele" (FOUCAULT, 2007, p. 453).

Fabricar a verdade é o poder do homem na constituição do saber moderno e essa verdade tem o poder de se inventar. Nesse sentido, a verdade é configurada nos limites da forma de conhecer que produz o efeito de devir, um saber que produz governamento da conduta a partir de regras-normas que incidem para um modo de ser. Um pensamento que projeta para o futuro formas de vida para o homem e para sua felicidade, permitindo que ele se reduplique nas relaçóes do saber que fabrica, pois conhece a si mesmo em sua empiricidade e, também, representa a si na ideia de um ser outro.

Para Foucault (2007), além da naturalização do mesmo, outro mecanismo ajuda inaugurar o pensamento moderno, a historicidade. Para o autor, o homem se reconhece na historicidade porque, para produzir-se historicizado, necessita descobrir a origem. Neste sentido, Foucault diz que “[...] não é a origem [...] que dá lugar à historicidade; é a historicidade que, na sua própria trama, deixa perfilar-se a necessidade de uma origem que lhe seria ao mesmo tempo interna e estranha" (2007, p. 455).

O efeito da historicidade se traduz porque "[...] o homem só se descobre ligado a uma historicidade já feita” (2007, p. 455), numa origem que por ele pode ser fabricada sendo a origem das coisas e do homem; mistura e efeito uma da outra. A necessidade da verdade no pensamento moderno se constitui porque o homem toma para si o poder de descrevê-la no espaço originário, atribuindo para si à função de, ao descrever a origem, poder dominar a verdade, tornando-se historicizado, tendo poder sobre e para determinar a história. Foucault diz:

[...] No pensamento moderno, o que se revela no fundamento da história das coisas e da historicidade própria ao homem é a distancia que escava o Mesmo, é o afastamento que o dispersa e o reúne nos dois extremos dele mesmo. É essa profunda espacialidade que permite ao pensamento moderno sempre pensar o tempo - conhecê-lo como sucessão, prometê-lo a si mesmo como acabamento, origem ou retorno. (FOUCAULT, 2007, p. 470). 
Conhecer a si em relação e representar-se a si numa ideia outra é o modelo de configuração que coloca em jogo os dois extremos dele mesmo. Este jogo passa pela origem, sucessão e acabamento em que é necessário dominar: um saber-verdade que recorta da experiência um saber possível; um saber-historicizado que procura a origem e a sucessão de espaço e de tempo para definir as condiçóes de possibilidade do saber reconhecido como verdade; um saber-discurso - práticas discursivas-, pois este precisa ser enunciado como verdade e operar na vida e nos modos de ser dos homens; e um saber-poder - práticas discursivas e não discursivas - que atravessam os homens e têm efeito em suas açôes e sobre as açôes dos outros.

O novo tipo de saber que se inaugura na época moderna se constitui nas condições de possibilidade para

[...] uma análise do que o homem é por natureza; são antes uma análise que se estende entre o que o homem é em sua positividade (ser que vive, trabalha e fala) e o que permite a esse mesmo ser saber (ou buscar saber) o que é a vida, em que consistem a essência do seu trabalho e suas leis, e de que modo ele pode falar. As ciências humanas ocupam, pois essa distancia que separa (náo sem uni-las), a biologia, a economia, a filologia daquilo que lhes dá possibilidade no ser mesmo do homem. (FOULCAULT, 2007, p. 488-489).

As condiçôes de possibilidade para essa maneira de pensar pela ordenação e pela normatização tornam possível o reconhecimento das experiências clínico- educacionais de Jean Itard como "origem" ou acontecimento histórico da emergência da Educação Especial.

Esse acontecimento - o encontro de Itard e Victor e a história da Educação Especial - só é possível porque a racionalidade moderna oferece as condiçôes de possibilidade internas - conceitos e métodos- para a realização deste saber; porque este saber está ancorado nas redes de necessidades deste tempo; e porque este saber, ao se configurar em prática discursiva, possibilita movimentar outra verdade que não se traduz só por progressos contínuos mas, também, por descontinuidades que vão constituir e determinar especificidades do saber, bem como outros saberes.

Saberes que retiram da invisibilidade aquilo que considera o homem não civilizado e que pode ser regrado para o advento de sua civilização, numa sociedade em que saber-poder reunem-se no plano da política capaz de designar maneiras de dirigir com açóes calculadas a conduta dos indivíduos através de técnicas disciplinares; e, segundo, como ação política ligada a práticas racionais-administrativas e de governo que buscam aperfeiçoar o espaço público, ordenando a convivência, controlando a circulação das coisas e pessoas, as práticas de regulação e seguridade.

É na ordem de um saber-poder individualizante que disciplina o corpo e o indivíduo e de um poder totalizante que, por meio de instituiçôes, controla a circulação das pessoas e gerencia o risco dos grupos destoantes, que Foucault vê emergir a noção de norma, a que Itard vai recorrer. A norma como modelo que opera na normalização disciplinar, demarcando a partir do modelo de ordenaçáo o normal e o anormal; e 
a norma - modelo de regulação - como curva normal que se expande funcionando como gerenciamento no conjunto da população, identificando o desviante, aquele que precisa receber por meio de açóes de governamento atendimento que garanta tanto a sua segurança como a segurança da sociedade.

Vê-se constituir, nesse cenário, os mecanismos de controle sendo movimentados pelos saberes da medicina, da sociologia, da psicologia e da pedagogia, modelos de disciplinamento do corpo e de controle das condutas; depois os modelos de segurança tendo como mecanismo a política do estado e a economia de governo que tinham como efeito as relações entre os indivíduos e a subjetivação de normas de conduta do indivíduo para consigo mesmo.

Nesse espaço da ordenação das relaçóes saber-poder constitui-se importante as instituiçôes educativas que vão desempenhar a função de colocar em funcionamento tecnologias de governo, elas são: a escola, os hospitais, as prisões e as tecnologias políticas de controle como a estatística, a fiscalização, as políticas de direitos e deveres. Instituiçóes educativas que prescindem de experiências como as desenvolvidas e relatadas por Itard.

\section{Educação Especial: ordenação de saberes e normalização da anormalidade}

A ordem saber-poder que nos detemos anteriormente nos habilita a pensar sobre um acontecimento que é considerado como "origem" da Educação Especial: o encontro e a produção de Jean Itard $^{2}$ na educação do menino Victor de Aveyron ${ }^{3}$, descrita em relatórios clínicos. Ao olhar para estes relatórios, fomos provocadas a compreender como a ordenaçáo de um saber e um modo de regulação da anormalidade foi tomado como possibilidade de governamento da anormalidade que vai se constituir na condição de possibilidade para sua emergência e a institucionalização de um campo de saber chamado de Educação Especial.

Os relatos de Itard nos permitem pensar sobre a constituição de um modo de pensar o espaço da ordem de um saber e da regulaçáo da anormalidade; pois o que nos interessa analisar são as condiçóes de possibilidade para que, neste encontro de Itard e Victor, se produzisse um lugar de enunciação para a Educação Especial como campo possível para se conhecer sobre a anormalidade e sobre a educabilidade do anormal.

Itard começa o Relatório I dizendo sobre o homem:

Lançado neste globo sem forças físicas e sem ideias inatas, sem condiçóes de obedecer por si só às leis constitucionais de sua organizaçáo, que o chamam à primeira noção do sistema dos seres, o homem só no seio da sociedade pode encontrar o lugar eminente que lhe foi assinalado na natureza, e seria sem a civilizaçáo, um dos mais fracos e menos inteligentes dos animais. (ITARD, 2000, p. 125).

Neste fragmento, Itard situa as condiçôes de possibilidade de suas ideias, apontando que o homem náo é um ser que pode ser lido, descrito e dito na ordem 
da história natural, pois se assim o fosse estaria ele entregue a morte, ou seria, dentre todos os seres da natureza o mais fraco, o menos inteligente. É, portanto, para Itard, a sociedade que vai dar ao homem um lugar na natureza, ou seja, é a ordem social que pode dizer sobre a natureza do homem.

Em sua empreitada com o selvagem de Aveyron, Itard vai rompendo com os estudos que naturalizam uma ordem de entendimento sobre o desenvolvimento do homem nas ideias inatas, numa metafísica, ou, ainda, numa medicina mecânica que náo considerava a medicina moral - antecessora da psicologia e psiquiatria. Era necessário para ele elaborar estratégias para o seu encontro com o selvagem que levasse em conta como intervir sobre o comportamento para a produçáo de comportamentos desejáveis.

Perceber o menino selvagem no espaço de uma ordem do saber de sua época era, para Itard, recusar "[...] a marcha defeituosa do estudo da ciência, entregue à mania das explicaçóes, à incerteza das hipóteses e ao trabalho exclusivo de gabinete, que a observaçáo náo contava nada"(ITARD, 2000, p. 126).

É, neste sentido, que Itard chama a medicina moral para comprovar a carência de experiências sociais como causa da anormalidade do selvagem e a possibilidade de ordenação de experiências que promovessem a curabilidade da debilidade. A ordem do saber, neste contexto, coloca em funcionamento para Itard a funçáo da norma, ou seja, como da norma é possível diferenciar o normal e o anormal e como pela norma é possível operar estratégias de normalização, ou seja, colocar o anormal na ordem da razão, do mesmo, do normal.

Diferentes anormalidades podem ser ordenadas tendo, somado a outros acontecimentos, o selvagem de Aveyron: a doença mental e a deficiência. Mas esta ordenação não se faz num fato histórico, mas como aponta Foucault, se faz história que produz o outro, os doentes mentais e a deficiência, e a necessidade de integraçáo desses na ordem da razáo, da normalidade.

Neste sentido, o espaço da ordem enquanto produção de verdade sobre a normalidade se dá pela produçáo da norma que estrategicamente possibilita, por meio de técnicas racionais, uma forma de distribuição e de identificação do anormal. Uma norma que também serve mais tarde para dizer da normalidade de ser um anormal, idiota, doente, que atualmente é conceituado como deficiente, autista...; ou seja, a identificação e a caracterizaçáo a partir dos critérios de uma norma capaz de reproduzir no sujeito aquilo que é a norma, a norma da deficiência, do autismo... e ao mesmo tempo as técnicas para modificá-los. Isso tem no encontro de Itard com o menino selvagem a emergência da norma que " [...] analisa, decompóe os indivíduos, os lugares, os tempos, os gestos, os atos, as operaçóes. Ela os decompôe em elementos que são suficientes para percebê-los, de um lado, e modificá-los de outro" (FOUCAULT, 2008, p. 74-75).

A norma como ordenação de saberes para a produção de sujeitos tem, portanto, um caráter de poder para instituir a sociedade de normalização que se incrementa por duas vias entrecruzadas - "a norma da disciplina e a norma da regulamentação" (FOUCAULT, 1999, p. 302). 
É no contexto deste espaço da ordem que a percepçáo sobre a anormalidade se modifica, da mesma forma que a ordem e a regulação da percepção sobre o doente mental também se alteram. As classificações se especializam e tornam possível separar a doença mental da deficiência, para Foucault:

[...] ao final do século XVIII, imbecilidade e demência se distinguirão não mais tanto pela precocidade da oposiçáo entre elas, nem mesmo pela faculdade atingida, como pelas qualidades que lhes pertencem e que comandaráo em segredo o conjunto de suas manifestaçóes. Para Pinel, a diferença entre imbecilidade e demência, em suma a que existe entre imobilidade e movimento. No idiota, há uma paralisia, uma sonolência de 'todas as funções do entendimento e das afecções morais'; seu espírito permanece imobilizado numa espécie de estupor. Na demência, pelo contrário, as funçóes essenciais do espírito pensam, mas pensam no vazio e, por conseguinte, com extrema volubilidade. A demência é como um movimento puro do espírito, sem consistência e nem insistência, uma fuga eterna que o tempo não consegue reter na memória: 'Sucessão rápida, ou melhor, alternativa, não interrompida de idéias e açóes isoladas de emoçóes ligeiras ou desordenadas, esquecendo-se tudo aquilo que lhes é anterior'. Nestas imagens, os conceitos de estupidez e imbecilidade se fixam, e com isso também o conceito de demência, que sai lentamente de sua negatividade e começa a ser considerado numa certa intuiçáo do tempo e do movimento. (FOUCAULT, 1978, p 289-290).

Pode-se perceber que Pinel $^{4}$ é um personagem importante para que se instale a diferenciação entre a doença mental e a deficiência - considerada estupidez ou imbecilidade - pois ele, no contexto da institucionalizaçáo - Hospital Bicêtre ${ }^{5}$-, estuda e analisa a doença ordenando-a "em uma estrutura geral de racionalidade em que se tratava da natureza e da ordem das coisas" (FOUCAULT, 2004, p. 169).

Neste sentido, Pinel, no século XVIII, ao se deter em estudar as doenças mentais e a anormalidade, o fazia no espaço da ordem que imprima a origem da doença na ordem do desvio. A doença e a anormalidade descritas e representadas em uma ordem como desordem da vida natural, a identidade da desordem, a ordem da desordem que tinha a possibilidade de ser representada em relaçáo à ordem das identidades normais.

No final do século XVIII, portanto, passou a ser necessário encontrar a ordem da doença no espaço da finitude para que um regime de verdade e instituiçóes pudessem ordenar uma classificação e um processo de ação terapêutica sobre o doente mental. Estas práticas para o deficiente, neste contexto, ainda eram negativas, pois eram a eles destinado o espaço da ordem da paralisia e da sonolência das funçóes do espírito/mente.

É neste sentido que Jean Itard encontra as condições de possibilidade para pensar as causas e a curabilidade do jovem selvagem Victor de Ayveron, e, de ser, posteriormente, considerado o personagem precursor da Educaçáo Especial. O contexto de oposição à representaçáo efetuada por Pinel ao "imbecil e estupido" num modelo de anormalidade representa que o quadro de ordenação por observação e descrição 
pode também ser utilizado para esse sujeito. Isso pode ser verificado na introdução do Relatório I - Da educação de um homem selvagem ou dos primeiros desenvolvimentos fisicos e morais do jovem selvagem do Aveyron (1801). Itard diz:

[...] antes de apresentar os pormenores e os resultados dessa medida, [cuidados e empreendimento feito com o selvagem de Aveyron] tenho de expor o ponto de que partimos, lembrar e descrever aquela primeira época, para apreciar melhor esta a que chegamos e, contrapondo assim o passado ao presente, determinar o que deve esperar do futuro. Portanto, obrigado a voltar a fatos já conhecidos, eu os explorarei rapidamente; e, para que náo achem que exagerei com o intuito de ressaltar aqueles que quero contrapor-lhes, eu me permitirei ressaltar aqui de uma maneira muito analítica a descriçáo que fez deles a uma sociedade científica, e numa sessão em que tive a honra de ser aceito, um médico tão favoravelmente conhecido por seu talento observador quanto por seus profundos conhecimentos das moléstias do intelecto. (ITARD, 2000, p. 131, grifo nosso).

Itard se refere nesta passagem a duas questôes. A primeira é a entrada de seu pensamento numa ordem do saber que constituía em pensar o empreendimento de educaçáo num patamar racional, tomando como ponto de partida o contraponto entre passado e presente, para assim projetar o futuro. Uma referência que toma a representação da representação como base de análise para colocar no devir a possibilidade de progresso, mas, sobretudo, no presente a função de prepará-lo tendo como referência a ordem da verdade sobre o desenvolvimento e a educaçáo daqueles anormais. A segunda questão é a contraposição em relação a Pinel que ele, Itard, pretende estabelecer, a partir dessa ordem de saber. Pinel é considerado talentoso observador, mas que tinha como modelo de análise o modelo descritivo da anormalidade no quadro ordenado em que a diferença colocava em evidência a desordem da vida natural.

Para Itard, o que Pinel pretendia na descriçáo do quadro da ordem da anornalidade do selvagem de Aveyron era classificá-lo no curso do enquadramento de uma estrutura geral, uma identidade entre os jovens anormais que também o identificava. Itard escreve as conclusôes de Pinel:

Iniciando com a exposição das funçôes sensoriais do jovem selvagem, o cidadão Pinel apresentou-nos seus sentidos reduzidos a tamanho estado de inércia que aquele desafortunado se encontrava, sob esse aspecto, bem inferior a alguns animais domésticos; seus olhos sem fixidez, sem expressão, errando vagamente de um objeto para outro, sem nunca se deter em nenhum; tão pouco instruídos aliás, e tão pouco exercitados pelo tato, que não distinguiam um objeto em relevo de um corpo em pintura; o órgão da audição insensível aos mais fortes ruídos bem como à música mais tocante; o da voz reduzido a um estado completo de mudez e só deixando escapar um som gutural e uniforme; o aroma dos perfumes e a exalaçáo mais fética dos lixos de que a cama esta repleta; enfim, o órgão do tato restrito às funções mecânicas da apreensão dos corpos. [...] Passando em seguida ao estado das funçóes intelectuais desse menino, o autor do relatório no-lo apresentou incapaz de atenção $[. .$.$] e, consequentemente, de todas as operaçóes da mente$ 
acarretadas pela primeira, desprovido de memória, de julgamento e de aptidão para imitação, e de tal modo limitado nas próprias ideias relativas às suas necessidades que ainda não conseguia abrir uma porta nem subir numa cadeira para alcançar os alimentos que eram levantados fora do alcance de sua máo; enfim, desprovido de qualquer meio de comunicação, não conferindo nem expressão nem intenção aos gestos e aos movimentos de seu corpo, [...] insensível a qualquer espécie de afeiçóes morais [...] toda a sua existência, numa palavra, uma vida puramente animal. (ITARD, 2000, p. 131-132) (grifo nosso).

É possível entender as condiçóes de possibilidade do pensar de Pinel, ou seja, a organização de um quadro da doença mental na forma de uma estrutura geral do desenvolvimento da anormalidade, tomando no campo do visível a identificação da diferença em relação a normalidade. Como nos aponta Foucault (2007a), da coisa, da observação da coisa, vem à palavra para representá-la. A finalização da citação "numa palavra" situa a condição de produção do saber, ou seja: a nomeação do visível pela identidade e diferença; a comparação e ordenação de um quadro classificatório; e a diferença produzindo o caráter metodológico para as coisas serem conhecidas num quadro que produz a identidade.

A palavra representando o ser/coisa, a representaçáo produzindo uma identidade que passa a nomear a anormalidade. Itard escreve que Pinel, ao relatar várias histórias das observaçóes das pessoas doentes mentais em Bicêtre, conseguiu estabelecer "entre estes infelizes e o apresentado pela criança que nos ocupa [o selvagem de Aveyron] as mais rigorosas comparaçóes, que tinham necessariamente como resultado uma identidade perfeita entre esses jovens idiotas e o selvagem de Aveyron" (ITARD, 2000, p. 132).

A produção de uma identidade universalista e essencializada da "estupidez e idiotia", neste tipo ordenado de anormalidade, conduzia um quadro de continuidade que, para Pinel, era "olhada como incurável" (ITARD, 2000, p. 132) o ser desta identidade "não era suscetível de espécie alguma de sociabilidade e de instrução" (ITARD, 2000, p. 132).

A não concordância de Itard em relação ao quadro contínuo da identidade anormal produzida por Pinel não se baseava simplesmente numa outra opção ou numa continuidade de pensamento que pudesse vislumbrar outro prognóstico ao selvagem de Aveyron, mas se situava nas condiçóes de possibilidade que a episteme do pensamento moderno fazia naquele momento emergir.

Itard diz: "ousei conceber algumas esperanças" (2000, p. 132), e sua ousadia pode ser traduzida no sentido de que ele assume uma duplicação dizendo: "Fundamentei-as [as esperanças] na dupla consideração da causa e da curabilidade deste idiotismo aparente" (ITARD, 2000, p. 132). Para tanto, duas possibilidades de análise surgem para Itard: a primeira é a análise do espaço do corpo do selvagem se usando da percepção meticulosa das suas condiçôes anatômicas, morfológicas e fisiológicas; e a segunda é o negligente contato deste com a vida e cultura humana que lhe permitisse apreender as condiçóes históricas, sociais e culturais do conhecimento humano que poderiam lhe prescrever um modo de ser humano. 
Esta construção realizada por Itard, em 1801, só era possível porque seu estudo do selvagem tinha ancoragem num modo de pensar - condiçôes de possibilidade do início do século XIX - que possibilitou estabilizar uma verdade sobre o sujeito anormal que estava na ordem do objeto e na ordem do discurso. Uma verdade manifestada através do corpo tanto do selvagem como da percepçáo do estudioso, as causas que determinam a identificação do desvio, do anormal; e uma verdade sustentada no discurso sobre a natureza e a história de um saber que tem como foco a bipolaridade normal-patológica, constituindo a norma, tâo prestigiada pelas ciências, pois em forma de conceitos e prescriçôes opera a intervenção da "curabilidade" desejada.

É, pois, nesta dupla causa-curabilidade que Itard procura um plano de ação e justifica o sucesso de seus cuidados considerando que "com efeito, relativamente ao pouco tempo que ele estava entre os homens, o selvagem de Aveyron era bem menos um adolescente imbecil do que uma criança de dez ou doze meses" (ITARD, 2000, p. 135). Isso colocava em outra ordem discursiva e normativa os cuidados que propôs ao selvagem.

A possibilidade de trazer a anormalidade do "estúpido/débil" para o campo da curabilidade, como se fazia com a doença mental, colocava-se para Itard como "um caso puramente médico e cujo tratamento competia a medicina moral" (ITARD, 2000, 135).

Se a medicina de Pinel estava no espaço da ordem de uma medicina classificatória em que a doença podia ser hierarquizada em famílias, gêneros e espécies (FOUCAULT, 2004), a medicina de Itard vai estar ligada à ciência clínica sendo um tipo de intervenção que, segundo Foucault (2004), ordena a clínica no discurso de uma "ciência positiva" que, ao invés de buscar saber o que tem o doente, coloca na ordem discursiva as causas, podendo operar os diagnósticos com grupos mais estáveis e universais das doenças e, para tanto, para seu tratamento.

Para prover o discurso científico da doença em suas causas, o espaço da ordem para a produção positiva do saber clínico se modifica, pois, ao invés da informação oferecida pelo doente, coloca-se no lugar a capacidade médica do olhar. Foucault diz que o "[...] progresso da observação, cuidado em desenvolver e ampliar a experiência, fidelidade cada vez maior ao que os dados sensíveis podem revelar, abandono dos sistemas e teorias em proveito de um empirismo mais científico" (2007, p. 151)

Esta nova perspectiva clínica envolve o diagnóstico das causas e o planejamento dos tratamentos a partir de um empirismo científico - um conhecimento válido pela experiência e verificado nela. Isso é encampado por Itard, pois sua experiência com o selvagem vai ser ordenada para uma atuação clínica "em que a disposição geral do saber" está no "jogo mútuo daquele que conhece e daquilo que é cogniscível" (FOUCAULT, 2004, p. 151). É isso que está em jogo quando Itard solicita a tutela do selvagem de Aveyron e o leva para um espaço domiciliar - condiçóes de possibilidade para que o tratamento clínico do anormal passe para a ordem do individual, da ação direta e corretiva do indivíduo. Uma ação que está para além do visível, pois considera ser possível conhecer e descobrir a profundidade daquilo que o selvagem é - causas - e do que pode ser transformado - curabilidade. 
Mas esta atuação clínica tem mais um elemento que é próprio das condições de possibilidades deste tempo, o século XIX, a medicina moral, que intervinha tendo como objeto de estudo a mente humana e o tratamento a partir de experiências comportamentais em ambientes suscetíveis para a ocorrência de desenvolvimento de comportamentos desejáveis. É neste contexto da clínica numa medicina moral que se encontra o espaço da ordem, uma espacialidade em que a norma de comportamentos desejáveis pode ser minuciosamente armada por um jogo de verdade científica que mais tarde fará surgir a psiquiatria e os modelos psicológicos que movimentam a ordem do poder disciplinar que permeia toda a sociedade moderna e suas instituiçóes de correçáo.

Para Foucault, um poder que em seu "modo terminal, capilar" como "uma última intermediação" se constitui em uma "modalidade pela qual o poder político, os poderes em geral vêm, no último nível, tocar os corpos, agir sobre eles, levar em conta seus gestos, os comportamentos, os hábitos, as palavras" (FOUCAULT, 2006, p. 50).

É assim que o selvagem de Ayveron a partir da intervenção de Itard passa a ser objeto e sujeito da ciência, não como indivíduo, mas como um caso em que se pode exercer certa funçáo dos discursos, das instituiçóes e das posiçóes e apresentarse como um caso que pode testar a maquinaria de ação do saber-poder a que todos podem ser suscetível. Isso fica evidente no Relatório II feito ao Ministro do Interior sobre os novos desenvolvimentos e o estado atual do selvagem de Aveyron (1806), quando o Dacier secretário do Instituto de France, escreve ao ministro o encaminhamento do Relatório de Itard:

O relatório do Sr. Itard contém, alias, a exposição de uma série de fenômenos singulares e interessantes, de observaçóes perspicazes e judiciosas, e apresenta uma combinaçáo de procedimentos instrutivos apropriados para fornecer dados à ciência e cujo conhecimento só poderia ser extremamente útil a todas as pessoas que se dedicam à educação da juventude. (ITARD, 2000, p. 181).

A função dada por Itard à medicina moral é uma função psicológica que seria colocada em funcionamento tendo como princípio inserir o sujeito selvagem na ordem da norma e, para tanto, iria se utilizar de açóes disciplinares que incidiriam sobre seu comportamento até que elas não fossem mais necessárias. Com o foco no desenvolvimento das funçôes dos sentidos, das funçôes do intelecto e das funçóes afetivas, Itard dispôs de cinco metas para o tratamento moral - intervenção sobre os comportamentos desviantes para adquirir consciência e comportamentos, aos moldes da experiência derivada dos sentidos - que de uma forma peculiar também identificava como educacional. Segundo Itard, "reduzi a cinco metas principais o tratamento moral ou a educação do selvagem de Aveyron” (2000, p. 135).

É, portanto, na relação entre medicina social, clínica terapêutica e educação el ou, na identificação delas como um mesmo processo, que se vê constituir o agrupamento de saberes determinados pelo espaço da ordem moderna, práticas discursivas e não discursivas sobre o anormal e seu atendimento. É no enquadramento de regras consideradas válidas para a constituiçáo de um saber sobre a anormalidade e o seu 
processo de normalizaçáo que levam Itard a compor aquilo que poderíamos chamar a educação do anormal, do selvagem, do não civilizado.

Atua como regra de validação, - conforme afirma Itard, as "diversas experiências que tentei, [...] numerosas observaçóes que recolhi, uma coleção de fatos[...]" (2000, p. 184) -, a experiência, as observaçóes e a organizaçáo de fatos que opera na formulação de saberes que dizem sobre a anormalidade a ser conhecida e tratada e, neste contexto, aparecem a posiçáo dos sujeitos que conhecem e os que devem ser conhecidos, bem como a distribuiçáo dos conceitos que colocam em movimento as formas de conhecer e a produção desses sujeitos.

Tendo como foco o desenvolvimento dos sentidos, do intelecto e das faculdades afetivas-sociais, Itard apresenta uma ordem ideal e final para o desenvolvimento do selvagem e é nela que irá operar o cuidado e a educaçáo dele. Aproximar o selvagem da infância e considerá-lo uma criança que não tinha desenvolvimento adequado em funçáo de sua existência isolada da sociedade foi uma leitura inicial para retirar a debilidade do selvagem da categoria de doença mental, uma das condiçóes de possibilidade que sua época lhe oferecia, pois segundo Foucault (2010), a "debilidade/idiotia" com os saberes da psiquiatria, da psicologia e da pedagogia no século XIX eram consideradas condiçôes de um sujeito com infância prolongada, pois estas características pertenciam a infância e não a doença, por, isso a pedagogia e não exclusivamente a medicina. A ordem dos saberes produzidos a partir da experiência de Itard com o selvagem estava na ordem da curabilidade e da adaptaçáo de um processo educativo à sua anormalidade.

Estes saberes médicos, psiquiátricos, psicológicos e pedagógicos que são possíveis a partir do século XIX e que são representados nos relatórios de Itard constituíram-se na rede de saber-poder que dinamizariam a sociedade urbana e industrial e as novas formas de governamentalidade da populaçáo que tomava forma e se instalava. E, neste contexto, as experiências sócio-clínico-pedagógicas na identificaçáo das causas e dos possíveis tratamentos da debilidade passaram a ser uma questão importante para o Estado e para o desenvolvimento da sociedade, pois ela representava lidar com a seguridade social, o controle sobre os indivíduos e a população, a vigilância em torno da produtividade individual e coletiva.

\section{Finalizando}

Os fragmentos dos relatórios de Itard analisados, considerando um ordenamento e a produção de uma verdade sobre saberes que se projetam num processo educativo de pessoas com deficiência, constituem um campo de saber denominado de Educação Especial. A análise pretendida neste artigo não nos oferece elementos para inferir sobre um modelo de institucionalizaçáo da deficiência e nem dos discursos atuais de um modelo/paradigma inclusivo do atendimento educacional da deficiência. No entanto, esta análise buscou conceber como uma determinada ordem do saber atua no sentido de apontar estratégias - finalidades e modos para o processo de normalização, bem como técnicas - modos de ação e intervenção - são considerados "fundadores" da Educação Especial. 
A ideia de um rompimento evolutivo com as práticas da Educação Especial do passado, como apontamos no início desta escrita, traduzidas nos paradigmas segregacionistas, interacionistas e inclusivistas, projetados nos estudos do presente do campo, nos apontam a superficialidade com que temos tratado do tema se considerarmos a Educaçáo Especial como um campo de saber. Ou seja, para pensar em uma ruptura dos modos de pensar a Educação Especial, não basta colocarmos nela o imperativo da inclusão.

O que podemos concluir, pelo menos momentaneamente, é que: esta é uma história, nada linear ou evolutiva, pois os relatórios de Itard, mais que um modo de pensar a deficiência e a sua educação, suscitam um acontecimento para a constituição de um campo de conhecimento que, como campo de saber, pode ser reconhecido em função da contingência histórica tendo como gênese a elaboração de um saber perspectivo; um saber que emerge; que tem um movimento e um propósito deliberado; um saber-poder que não apaga o lugar, o tempo e o sentido das condiçóes de possibilidades em que é possível dizer da fundação da Educação Especial e de como precisamos, ainda, pensar esse campo do saber, no presente, numa possível ordem da continuidade, saberes verdadeiros tomados no presente para identificar, classificar e caracterizar aquele que [e determinado pela norma da deficiência.

\section{Referências}

CANDIOTO, C. Foucault e a crítica do sujeito e da história. In: RAGAO, M.; MARTINS, A. Revista Aulas, n. 3, dez. 2006/mar. 2007, p. 1-6. Disponível em: <http://www.unicamp.br/ aulas/revista_aulas/foucault/dossieFoucault.pdf $>$. Acesso em: 30 out. 2012.

FOUCAULT, M. Microfísica do poder. Rio de Janeiro: Editora Grall, 1979.

. Vigiar e punir: história da violência nas prisōes. Petrópolis: Editora Vozes, 1987.

Em defesa da sociedade. São Paulo: Martins Fontes, 1999.

O nascimento da Clínica. Rio de Janeiro: Florense Universitária, 2004.

O poder Psiquiátrico. São Paulo: Martins Fontes, 2006.

As palavras e as coisas. São Paulo: Martins Fontes, 2007.

Segurança, território, populaçáo. São Paulo: Martins Fontes, 2008.

O governo dos vivos. São Paulo: Achiamé, 2010.

ITARD, J. Relatório I: Da educação de um homem selvagem ou dos promeiros desenvolvimentos físicos e morais do jovem selvagem do Aveyron. In: BANKSLEITE, L.; GALVÃO, I. A educaçáo de um selvagem: as experiências pedagógicas de Jean Itard. São Paulo: Cortez, 2000, pp. 123-177.

. Relatório II: Relatório feito a sua excelência o ministro do interior sobre os novos desenvolvimentos e o estado atual do selvagem de Aveyron.In: BANKSLEITE, L.; GALVÃO, I. A educaçáo de um selvagem: as experiências pedagógicas de Jean Itard. São Paulo: Cortez, 2000, pp. 179-229.

MACHADO, R. Foucault, a ciência e o saber. Rio de Janeiro: Jorge Zahar Ed., 2006.

MANTOAN, M. T. E. Inclusão Escolar - caminhos e descaminhos, desafios, perspectivas. In: Ensaios pedagógicos. Brasília: Ministério da Educação, Secretaria de Educação Especial, 2007, p. 11-16.

\section{Notas}

${ }^{1}$ Foucault busca analisar as descontinuidades do modo de pensar. Uma história do saber que tem privilegiado alguns modos de dizer as coisas em detrimento de outros modos; tem privilegiado o discurso da razão sobre a desrazão e do mesmo sobre o outro. 
2 Jean-Marc-Gaspard Itard: foi um médico psiquiatra francês no século XIX que tornou-se tutor de um menino selvagem, com quem desenvolveu uma série de terapias educacionais tendo como objetivo tornar o selvagem num humano civilizado.

${ }^{3}$ Victor de Aveyron: uma criança que cresceu na selva, encontrada com cerca de 10 anos na França em 1798. Seu comportamento ao ser encontrado se assemelhava a de um animal. Capturado pela polícia, ficou algum tempo em orfanato e mais tarde foi conduzido ao Hospital de Bicêtre em Paris para ser estudado e civilizado. Um primeiro diagnóstico dado por Pinel foi o de idiotia não suscetível a socialização e educação.

${ }^{4}$ Philippe Pinel foi um médico que entre os séculos XVII e XIX foi responsável por uma reforma psiquiátrica na França tomando como referência produção e descrição da doença mental. Ou seja, produziu um conjunto de enunciados em que poderia descrever seres humanos que sofriam de perturbaçóes mentais como doentes. Por ter atingido este feito na descriçấo e caracterização de algumas perturbaçóes mentais, é tomado como o pai da psiquiatria.

${ }^{5}$ Foi um hospital do subúrbio de Paris originalmente planejado como hospital militar em 1634 que em 1885 recebeu o nome de Hospice de Bicêtre e como orfanato/asilo de doentes mentais foi o espaço de trabalho de Pinel e de Itard.

\section{Correspondência}

Leandra Bôer Possa - Universidade Federal de Santa Maria, Cidade Universitária - Centro de Educaçáo, Predio 16, Sala 3150A, Av. Roraima, 1000, Bairro Camobi, CEP: 97105-900, Santa Maria - Rio Grande do Sul, Brasil.

E-mail: leandrabp@gmail.com

Recebido em 24 de agosto de 2016

Aprovado em 30 de setembro de 2016 